\title{
Research on RMST Trade-off Optimization of Chemical Defense Smoke Vehicle Based on System Efficiency
}

\author{
Gao Xiaohui, Han Chaoshuai, Pan Enchao, Li Faming \\ Academy of Military Science, Chemical Defense Research Institute, Beijing
}

Keywords: chemical defense smoke vehicle; system efficiency; RMST design trade-off; readiness rate; mission reliability

\begin{abstract}
For modern new-type chemical defense smoke equipment, quality has become a major difficulty in the formation of combat effectiveness. Therefore, on the basis of analyzing the related research, this paper put forward a design trade-off method which is applicable to the quality of the design development stage and the equipment development, that is RMST trade-off optimization method based on system efficiency. Firstly, based on the characteristics of smoke vehicle and the connotation of system efficiency, the paper analyzes the influence factors of the system efficiency and constructs the conceptual model of the system efficiency. Second, taking series complex structure as an example, it builds mission-reliability model and the model of readiness rate mode suitable for current system of supply guarantee, then obtains the system efficiency mathematical model under the structure; Finally, through the RMST general simulation process and the constraint value of the multi-objective decision variables, the system efficiency optimization simulation trade-off model is built to provide the basic algorithm for the next stage of the simulation design for real equipment.

At present, there is a great amount of studies of RMST trade-off optimization, which generally can be divided into RMST trade-off based on top-level design index [1-3], RMST trade-off based on cycle cost [4-6], and RMST trade-off based on system efficiency [7-9]. According to this paper, it is believed that the RMST of equipment system is decided by quality characteristics of various basic constitutional units and structural layout of equipment system, and the trade-off and optimization of RMST index is not only applied to demonstration stage, also promoted and used in the stage of development and design. Therefore, this paper, according to actual FLQM of chemical defense smoke vehicle in our army, based on previous studies, constructs RMST trade-off mode and simulation dynamics mode based on system efficiency suitable for the stage of development and design, and proposes RMST trade-off analysis process and bound variables of decision-making, providing research foundation for implementing the design of new-type equipment.
\end{abstract}

\section{System Efficiency Model of Chemical Defense Smoke Vehicle}

\subsection{The influence factors of system efficiency}

The anti-chemical smoke vehicle belongs to the intermittent equipment system, which is basically in alternative working and halt in life cycle [10]. The inherent ability of smoke vehicle mainly refers to the comprehensive performance of equipment smoke, protection, maneuvering, index control, etc. The impact of RMST design and equipment performance design is mainly reflected in the selection of basic components and infrastructure. Whereas, RMST trade-off optimization is aimed at optimizing the layout structure, and generally does not change its basic components and architecture, so the inherent ability can be set as constant when building a system efficiency model with the goal of RMST trade-off optimization.

Therefore, on the basis of analyzing influence factors of system efficiency of smoke vehicle, the model can be built as shown in Equation (1).

$$
E=P \cdot D \cdot C
$$


In Equation (1), E refers to system efficiency; P refers to the parameter of readiness rate, which indicates the integrity of the smoke vehicle in mission preparation; D refers to the parameter of mission credibility, which shows the probability of smoke vehicle to be successfully used to accomplish mission at any time on the basis of successful dispatch; $\mathrm{C}$ refers to the inherent ability parameters of smoke vehicle.

Based on the current supply guarantee system for spare parts of chemical defense equipment, this paper constructs a mathematical model of the system efficiency under the general series of complex structures, which provides a basis for the implementation of RMST trade-off of anti-chemical smoke vehicle. When constructing the model, name $c$ as the identifier of the series structure, $b$ as the identifier of the redundant voting structure, and $y$ as the identifier of the preventive maintenance.

\subsection{The model of mission reliability parameter}

Mission reliability refers to the ability for equipment to complete the mission without failure or repair in time after failure, and the model is shown in Equation (2).

$$
D(t)=R(t)+(1-R(t)) \cdot \varphi_{k} \cdot M(t)
$$

Wherein, $R(t)$ indicates the reliability of the equipment to perform mission at the time t; $\varphi_{k}$ indicates the failure detection isolation rate; $M(t)$ indicates the maintenance function after the failure.

\subsubsection{The calculation model of mission reliability}

According to mission reliability model of simple series structure and redundant voting module, the mission reliability model of series complex structure can be deduced as shown in Equation (3).

$$
\left.R_{S}(t)=e^{-\sum_{i=1}^{n_{c}} \lambda_{i} t} \prod_{j=1}^{n_{b}} \sum_{g=1}^{o_{j}-k_{j}} C_{o_{j}}^{g}\left(1-e^{-\lambda_{j} t}\right)^{g} e^{-\left(o_{j}-g\right) \lambda_{j} t}\right)
$$

Wherein, $n_{c}$ is the number of modules in the series structure in the system; $n_{b}$ is the number of redundant structures in the complex system; $o_{i}$ is the number of units in the $\mathrm{i}$-th redundant module; $k_{i}$ is the number of voting units in the $\mathrm{i}$-th redundant structure; $\lambda_{i}$ is the failure rate in the i-th module.

\subsubsection{The calculation model of maintenance}

Because the calculation model of failure detection rate in [12] is scientific and correctly deduced, this paper uses the model (recorded as $\varphi_{k s}$ ) in this paper to construct the mission reliability model, which is shown in Equation (4), based on studies on mission reliability and maintenance parameter model.

$$
D_{s}\left(t_{s}\right)=\left\{\begin{array}{c}
\left.e^{-\sum_{i=1}^{n_{c}} \lambda_{c i} t_{s}} \prod_{j=1}^{n_{b}} \sum_{g=1}^{o_{j}-k_{j}} C_{o_{j}}^{g} \cdot\left(1-e^{-\lambda_{b j} t_{s}}\right)^{g} e^{-\left(o_{j}-g\right) \lambda_{b j} t_{s}}\right) \cdot \\
{\left[1-\prod_{i=1}^{n_{c}}\left(1-e^{-\mu_{c i} t_{s}}\right) \cdot \prod_{j=1}^{n_{b}}\left(1-e^{-\mu_{b j} t_{s}}\right)^{o_{j}} \cdot \varphi_{k s}\right]} \\
+\prod_{i=1}^{n_{c}}\left(1-e^{-\mu_{c i} t_{s}}\right) \cdot \prod_{j=1}^{n_{b}}\left(1-e^{-\mu_{b j} t_{s}}\right)^{o_{j}} \cdot \varphi_{k s}
\end{array}\right\}
$$

Wherein, $t_{s}$ is the average mission continuous working time of the system; other parameters are the same as above.

\subsection{The model of readiness rate parameter}


The readiness rate indicates that the conditions of equipment in mission preparation [13]. To achieve successful dispatch, the failure must be repaired before the next dispatch or the previous mission with no failure. Therefore, the readiness rate can be expressed not only by the ratio of the number of successful dispatches to the total number of dispatches, also for smoke vehicle, can be shown by the model in Equation (5).

$$
P_{O R}=\frac{t_{d}}{t_{d}+E\left(\tilde{t}_{m}\right)+E\left(\tilde{t}_{p}\right)+E\left(\tilde{t}_{f}\right)}
$$

Wherein, $t_{d}$ is the specified or allowed maintenance downtime; $E\left(\tilde{t}_{m}\right)$ is the average maintenance delay time, indicating the average value of actual maintenance time exceeding the specified maintenance time or re-dispatch time; $E\left(\tilde{t}_{p}\right)$ is the average spare part delay time, indicating the average turnover time of waiting spare parts due to the lack of spare parts on site; is the average preventive maintenance delay time, indicating the average time value of equipment delay due to periodic maintenance.

\subsubsection{The calculation model of delay time due to periodic maintenance}

The failure probability of each module is only related to this module, independent of the integrated system. Therefore, when the average maintenance delay time of each module is integrated, the average maintenance delay time of each module cannot be simply added. It is necessary to clarify the relationship between the failure probability of the system and the failure probability of each module, and obtain average maintenance delay time of the entire series complex structure by replacing their own failure probability with the independent failure of each module in the system. Suppose whether it is series module or redundant module, once any failure occurs, it is recorded as a failure, that is, the redundant structure equivalence is taken as the series unit of the system, and the probability of failure of the integrated system is shown.

$$
f_{s}(t)=1-\prod_{i=1}^{n_{c}+n_{b}}\left[1-f_{i}(t)\right]
$$

The relationship between the failure probability of the system and the failure probability of each module is shown in Equation (6).

$$
h_{i}(t)=f_{s}(t) \cdot \frac{\operatorname{In}\left(\frac{1}{1-f_{i}(t)}\right)}{\sum_{i=1}^{n_{c}+n_{b}} \operatorname{In}\left(\frac{1}{1-f_{i}(t)}\right)}=\left[1-\prod_{i=1}^{n_{c}+n_{b}}\left[1-f_{i}(t)\right] \frac{\operatorname{In}\left(\frac{1}{1-f_{i}(t)}\right)}{\sum_{i=1}^{n_{c}+n_{b}} \operatorname{In}\left(\frac{1}{1-f_{i}(t)}\right)}\right.
$$

Thus, the model of average maintenance delay time in series complex structure is shown in Equation (7).

$$
E_{s}\left(\tilde{t}_{m}\right)=\frac{1-\prod_{i=1}^{n_{c}+n_{b}}\left[1-f_{i}(t)\right]}{\sum_{i=1}^{n_{c}+n_{b}} \operatorname{In}\left(\frac{1}{1-f_{i}(t)}\right)} \cdot\left\{\sum_{i=1}^{n_{c}} \frac{\operatorname{In}\left(\frac{1}{1-f_{i}(t)}\right) \cdot e^{-\mu_{c i} t_{d}}}{\mu_{c i}}+\sum_{i=1}^{n_{b}} \sum_{j=1}^{o_{i}} \frac{\operatorname{In}\left(\frac{1}{1-f_{i}(t)}\right)(-1)^{j+1} C_{o_{i}}^{j} e^{-j \mu_{b i} t_{d}}}{j \mu_{b i}}\right\}
$$

\subsubsection{The calculation model of average spare part delay time}

The premise that the average spare part delay time is not 0 is that failure occurs in the system and the spare parts required for maintenance are lack on site. Under the three-level supply system of on-site, battle-level equipment warehouse and strategic-level equipment warehouse, the calculation model of the average spare part delay time of module $I$ is shown in Equation (8).

$$
E_{i}\left(\tilde{t}_{p}\right)=f_{i}(t) \cdot\left[t_{p 1 i}(t) \cdot \bar{P}_{1 i}\left(t_{0}\right) \cdot P_{2 i}\left(t_{x}\right)+t_{p 2 i}(t) \cdot \bar{P}_{1 i}\left(t_{0}\right) \cdot \bar{P}_{2 i}\left(t_{0}\right)\right]
$$

Wherein, $t_{p 1 i}$ is the turnover time for battle-level equipment warehouse to temporarily acquire 
the spare parts of the module $\mathrm{i} ; t_{p 2 i}$ is the turnover time for the strategic-level equipment warehouse to temporarily acquire the spare parts of the module $\mathrm{i} ; P_{1 i}(t)$ is the probability of spare parts guarantee on site for the module $\mathrm{i}$ in the time $t ; P_{2 i}(t)$ is the probability of spare parts guarantee for battle-level equipment warehouse for the module $\mathrm{i}$ in the time $t ; t_{0}$ is the accumulated working time of equipment in the period of supply guarantee of spare parts; $t_{x}$ is the average working time of the equipment in the period of supply guarantee minus the average time of the exhaustion of the equipment spare parts on site. In addition to the effects of uncontrolled factors such as transportation and natural disasters, $t_{p 1 i}$ and $t_{p 2 i}$ can basically maintain a constant value, so the two can be assumed to be constant in the design.

Since the spare parts supply only considers the number of spare parts instead of the series or redundant structure, the series structure and the redundant voting structure can share a spare part guarantee probability model shown.

$$
P_{i}(t)=\frac{1}{t} \int_{0}^{t} e^{-\lambda_{i} t} \sum_{j=0}^{m} \frac{\left(\lambda_{i} t\right)^{j}}{j !} d t
$$

Thus, the calculation model of spare part delay time in series structure can be obtained from Equation (6) and (8), shown in Equation (9).

$$
E_{s}\left(\tilde{t}_{p}\right)=\sum_{i=1}^{n_{c}+n_{b}} h_{i}(t) \cdot\left\{\begin{array}{c}
t_{p 1}\left[1-\frac{1}{t_{0}} \int_{0}^{t_{0}} e^{-\lambda_{i} t} \sum_{j=0}^{m_{1 i}} \frac{\left(\lambda_{i} t\right)^{j}}{j !} d t\right]\left[\frac{1}{t_{x}} \int_{0}^{t_{x}} e^{-\lambda_{i} t} \sum_{j=0}^{m_{2 i}} \frac{\left(\lambda_{i} t\right)^{j}}{j !} d t\right] \\
+t_{p 2}\left[1-\frac{1}{t_{0}} \int_{0}^{t_{0}} e^{-\lambda_{i} t} \sum_{j=0}^{m_{11}+m_{2 i}} \frac{\left(\lambda_{i} t\right)^{j}}{j !} d t\right]
\end{array}\right\}
$$

Wherein, $m_{1 i}$ is the storage capacity of the i-th module equipment regularly distributed spare parts of the repair organization of this level; $m_{2 i}$ is the number of equipment regularly distributed spare parts for the i-th module of the battle-level equipment warehouse; $m_{3 i}$ is the quantity of equipment regularly distributed spare parts for the i-th module of the strategic-level equipment warehouse; $t_{0}$ is the accumulated working time of the equipment system during the regular distribution period of the spare parts of the equipment; $t_{x}$ is the average time of accumulated working time in the supplementary supply guarantee period minus the average time of the exhaustion of the spare parts of the equipment on site. The mode is presented.

$$
t_{x}=t_{0}\left(1-\frac{1}{t_{0}} \int_{0}^{t_{0}} e^{-\lambda_{i} t} \sum_{j=0}^{m_{1 i}} \frac{\left(\lambda_{i} t\right)^{j}}{j !} d t\right)
$$

\subsubsection{The calculation model of average delay time due to preventative maintenance}

The average preventive maintenance delay is different from the maintenance delay and spare parts delay. The preventive maintenance interval is fixed. The interval between the maintenance of the smoke vehicle is set as ${ }^{T_{F}}$, the maintenance time parameter of each medium repair or overhaul as ${ }^{t_{f}}$, and the calculation model of average preventive maintenance delay time as Equation (10).

$$
E\left(\tilde{t}_{f}\right)=\sum_{i=1}^{n_{y}} E_{i}\left(\tilde{t}_{f}\right), \quad E_{i}\left(\tilde{t}_{f}\right)=\left\{\begin{array}{cc}
\frac{t_{s}\left(t_{f i}-t_{d}\right)}{T_{F i}} & t_{f i}>t_{d} \\
0 & t_{f i} \leq t_{d}
\end{array}\right.
$$

Thus, the calculation mode of readiness rate in series complex structure is shown in Equation (11). 


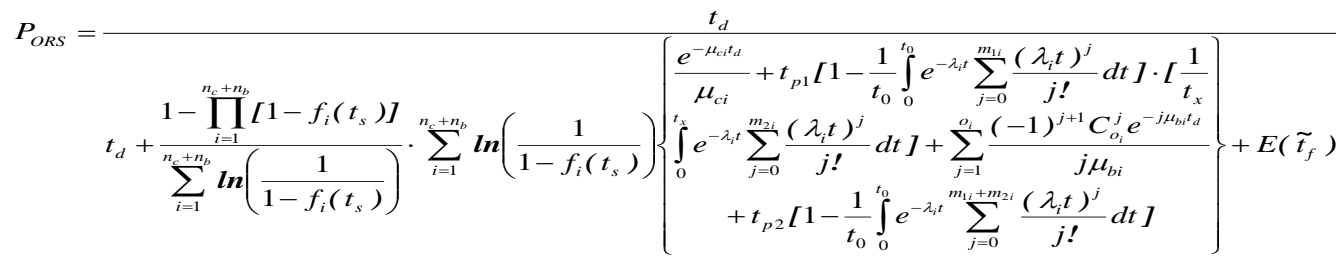

\section{RMST Trade-off Optimization}

According to the system efficiency model, there are 19 basic indicator data that need to be obtained, which are mainly determined by the component types and system structure layout selected by the equipment. The final object of the RMT trade-off optimization analysis is these 19 indicators. In engineering practice, if RMST trade-off of anti-chemical smoke vehicle is conducted with the goal of system efficiency, the three methods are generally used, including comparative trade-off analysis method, sensitivity trade-off analysis method and simulation trade-off optimization method. The first two are simple and there are many studies, referred in [14-16]. Thus, simulation trade-off optimization is demonstrated and verified in this paper.

Table 1 Definitions of basic parameters in simulation model of system efficiency

\begin{tabular}{|c|c|c|c|c|c|}
\hline No. & Name of parameters & Symbol & No & Name of parameters & Symbol \\
\hline 1 & $\begin{array}{l}\text { The number of modules in } \\
\text { series structure }\end{array}$ & nc & 11 & $\begin{array}{l}\text { The quantity of equipment } \\
\text { regularly distributed spare parts for } \\
\text { the i-th module of the } \\
\text { strategic-level equipment } \\
\text { warehouse }\end{array}$ & $\mathrm{m} 3 \mathrm{i}$ \\
\hline 2 & $\begin{array}{l}\text { The number of modules in } \\
\text { redundant voting structure }\end{array}$ & $\mathrm{nb}$ & 12 & $\begin{array}{l}\text { The turnover time of spare parts } \\
\text { from warehouse of this level to } \\
\text { maintenance site }\end{array}$ & tp1 \\
\hline 3 & $\begin{array}{l}\text { The number of units in the } \\
i \text {-th redundant module }\end{array}$ & oi & 13 & $\begin{array}{l}\text { The turnover time of supply } \\
\text { module from strategic-level } \\
\text { equipment warehouse to } \\
\text { maintenance site }\end{array}$ & tp2 \\
\hline 4 & $\begin{array}{l}\text { The number of voting } \\
\text { units in the } i \text {-th redundant } \\
\text { module }\end{array}$ & ki & 14 & $\begin{array}{l}\text { The accumulated working time of } \\
\text { equipment system in regularly } \\
\text { distributed cycle of spare parts }\end{array}$ & t0 \\
\hline 5 & $\begin{array}{l}\text { The failure rate of unit in } \\
\text { the } i \text {-th module }\end{array}$ & ai & 15 & $\begin{array}{l}\text { The number of projects with } \\
\text { preventative maintenance of } \\
\text { complex system }\end{array}$ & ny \\
\hline 6 & $\begin{array}{l}\text { The repair rate of unit } \\
\text { disassembly and assembly } \\
\text { in the } i \text {-th module }\end{array}$ & ui & 16 & $\begin{array}{l}\text { The preventative maintenance cycle } \\
\text { of the } i \text {-th sub-module }\end{array}$ & TFi \\
\hline 7 & $\begin{array}{l}\text { The average mission } \\
\text { continuous working time } \\
\text { of the system }\end{array}$ & ts & 17 & $\begin{array}{l}\text { The average preventative } \\
\text { maintenance time of the } i \text {-th } \\
\text { sub-module }\end{array}$ & tfi \\
\hline 8 & $\begin{array}{l}\text { Specified or allowed } \\
\text { maintenance and } \\
\text { downtime }\end{array}$ & $\mathrm{td}$ & 18 & $\begin{array}{l}\text { The frequency ratio of site replace } \\
\text { module of the } i \text {-th sub-module and } \\
i \text {-th failure mode }\end{array}$ & Aij \\
\hline 9 & $\begin{array}{l}\text { The storage capacity of } \\
\text { the i-th module equipment } \\
\text { regularly distributed spare }\end{array}$ & $\mathrm{m} 1 \mathrm{i}$ & 19 & $\begin{array}{l}\text { The number of modules replaced } \\
\text { due to BITE isolated failure }\end{array}$ & $\mathrm{Nk}$ \\
\hline
\end{tabular}




\begin{tabular}{|c|c|c|}
\hline & $\begin{array}{l}\text { parts of the repair } \\
\text { organization of this level }\end{array}$ & \\
\hline 10 & $\begin{array}{l}\text { The number of equipment } \\
\text { regularly distributed spare } \\
\text { parts for the i-th module } \\
\text { of the battle-level } \\
\text { equipment warehouse }\end{array}$ & $\mathrm{m} 2 \mathrm{i}$ \\
\hline
\end{tabular}

\subsection{The simulation process of trade-off analysis}

The simulation-based trade-off analysis method [17], according to the system efficiency mathematical model, is to adopt the system dynamics simulation principle, analyze the relationship between system efficiency and RMST indicators, and weighs the RMST indicator scheme under the optimal system efficiency, also can comparatively analyze the current scheme and optimal scheme to provide decision-making basis for the design of RMST indicators. The advantage of the simulation trade-off optimization method is that the optimal configuration can be obtained in as many schemes as possible, but it is necessary to provide as many boundary conditions as possible by simulation trade-off optimization to ensure the technical feasibility of the scheme as much as possible. In this paper, Matlab software is used to construct the optimization simulation algorithm of system efficiency, and the trade-off analysis is carried out through the process of "experiment design-simulation operation-efficiency optimization-result analysis”.

\subsection{The constraint of multi-objective decision variables}

The selection of decision variables and the definition of constraint values are especially important for the final structure of simulation optimization. This paper design the requirements of the standard specification according to the anti-chemical smoke vehicle RMST [18], combined with the actual development requirements of the current equipment, set the eight variables as decision variables of the simulation trade-off, and set the threshold and constraint values, shown in Table 2.

Table 2 The setting of decision variables, the threshold and constraint values of simulation optimization of system efficiency

\begin{tabular}{|c|c|c|c|c|}
\hline No. & Name of variable & Symbol & $\begin{array}{c}\text { Threshold } \\
\text { value }\end{array}$ & Constraint value \\
\hline 1 & System efficiency & E & $0 \sim 1$ & $\geq 0.75$ (optimal) \\
\hline 2 & Readiness rate & POR & $0 \sim 1$ & $\geq 0.85$ \\
\hline 3 & $\begin{array}{c}\text { The average failure repair } \\
\text { time }\end{array}$ & MTTR & $\geq 0 \mathrm{~h}$ & $\leq 10 \mathrm{~h}$ \\
\hline 4 & The average failure interval & MTBCF & $\geq 0 \mathrm{~h}$ & $\geq 500 \mathrm{~h}$ \\
\hline 5 & $\begin{array}{c}\text { The average maintenance } \\
\text { delay time }\end{array}$ & MLDT & $\geq 0 \mathrm{~h}$ & $\leq 50 \mathrm{~h}$ \\
\hline 6 & $\begin{array}{c}\text { The average spare part } \\
\text { delay time }\end{array}$ & Tp & $\geq 0 \mathrm{~h}$ & $\leq 100 \mathrm{~h}$ \\
\hline 7 & $\begin{array}{c}\text { The isolation rate of system } \\
\text { failure detection }\end{array}$ & XS & $0 \sim 1$ & $\geq 0.85$ \\
\hline 8 & $\begin{array}{c}\text { The guarantee rate of } \\
\text { system spare parts }\end{array}$ & PS & $0 \sim 1$ & $\geq 0.70$ \\
\hline
\end{tabular}

\section{Conclusion}

According to the actual demand of insufficient methods and technologies for the quality of anti-chemical smoke vehicle, this paper, analyzes the main methods of RMST trade-off at home and abroad, proposes RMST trade-off of anti-chemical smoke vehicle suitable for development and design, and constructs the parameter model of RMST system efficiency and simulation model of 
system dynamics in series complex structure, aiming to promote the implementation of RMST trade-off and realizing the optimal configuration of performance of anti-chemical smoke vehicle and RMST performance.

\section{References}

[1] Ding Dinghao. The System Design of Mission Capable Rate of AWACS Fleet's Information Equipment [J]. Electronic Product Reliability and Environmental Testing, 2015,33(2):1-5.

[2] Zhang Shinian, Yan Shiyuan, Zhang Guobin et al. Storage life synthesis evaluation method of guided missile weapon based on mission capable rate [J]. Systems Engineering - Theory \& Practice, 2015,35(2):513-520.

[3] Ding Dinghao, Lu Jun. Theoretical Model and Design Technique of Guarantee for Equipment Lifecycle [M]. Publishing House of Electronics Industry, 2011.

[4] Qiao Sanbao, Geng Junbao, Sun Linkai et al. Warship's RMS based on LCC of Balance Technology Analysis [J]. Equipment Manufacturing Technology, 2012,(1):90-92.

[5] Jianyun Hong, Bingwen Li, Jianwu Wang et al. The application of LCC technology in hyperstatic hydraulic support[C].//2011 Second International Conference on Mechanic Automation and Control Engineering. [v.1].2011:7793-7795.

[6] Ron J. van Baaren,Klaas Smit.Design for RMS/LCC the development of a design model[C].//International Symposium on Product Quality \&amp;amp; Integrity.1999:330-335.

[7] Wang Qinglong, Wang Zhixue, He Hongyue et al. Modeling and analysis method to C4ISR system for efficiency requirements based on fuzzy cloud model [J]. Systems Engineering and Electronics, 2016,38(9):2065-2071.

[8] Han Kun, He Chengming, Liu Weiwei, Shen Ying. Trade-off Analysis of Reliability, Maintainability, Supportability and Testability of Armored Vehicle Based on System Effectiveness [J]. Acta Armamentarii, 2014,35(2):268-272.

[9] Wang Zhixue, Dong Qingchao, Zhang Weizhong et al. Goal-oriented conceptual modeling and consistency checking for C4ISR system effectiveness analysis [J]. Systems Engineering - Theory \& Practice, 2013,33(9):2381-2389.

[10] Yang Yonggang, Feng Huazhong, Zhang Liang et al. Development of vehicle mounted large area smoke disinfection machine [J]. Chinese Journal of Disinfection, 2016,33(12):1181-1184.

[11] Zhao Yueqiang, Mai Qiang, Xu Qingyan et al. Dependability modeling research of air-defense missile weapon systems [J]. Systems Engineering and Electronics, 2016,38(12):2777-2784.

[12] Ding Dinghao. The Main Purposes and Implementation of Design for Testability [J]. Electronic Product Reliability and Environmental Testing, 2014,32(3):1-5.

[13] Wang Jing, Hong Dongpao, Lin Shumao, Cao Xiaohong. Study on Quantitative Supportability Parameters Set of Equipment [J]. Missiles and Space Vehicles, 2016,345(03):55-58.

[14] Tang Ke, Wang Cunwei. Research on the Influencing Factor of Terminal-sensitive Projectile Based on SPA [J]. Command Control \& Simulation, 2010,32(6):52-54.

[15] Zhou Wei, Xia Guoping, Yan Ning et al. Multi-attribute evaluation method for missile weapon system effectiveness based on WGA operator [J]. Journal of Beijing University of Aeronautics and Astronautics, 2008,34(10):1232-1235.

[16] Su Yongding, Qiu Jing, Yang Peng et al. Missile Testability Requirement Analysis and Index Determination Oriented to Mission [J]. Journal of National University of Defense Technology, 2011,33(2):125-129.

[17] Du Haidong, Wu Wei, Cao Junhai, Xu Dai. Simulation Research for RMS Indexes of Armored 
Equipment Based on System Effectiveness Analysis [J]. Journal of System Simulation, 2013,25(08):1947-1951.

[18] Standards for Reliability, Maintainability, Supportability and Testability of Equipment (26 items). GJB1909.1-1994, GJB 1901A-2009, GJB-368.1-6, GJB 2547A-2012 and so on. 